\title{
Prevalence of Mycobacterium avium and Mycobacterium tuberculosis in Blood Cultures of Brazilian AIDS Patients After Introduction of Highly Active Retroviral Therapy
}

\author{
S.M.Nakatani ${ }^{1}$, I.J.T. Messias-Reason ${ }^{2}$, \\ M.Burger $^{1}$ and C.A.Cunha ${ }^{3}$
}

\begin{abstract}
LACEN (Central Laboratory of the State of Paraná) ${ }^{1}$; Department of Clinical Pathology, Federal University of Paraná ${ }^{2}$; Department of Infectology, Federal University of Paraná ; Curitiba, PR, Brazil
\end{abstract}

\begin{abstract}
The use of highly active antiretroviral therapy (HAART) for the treatment of HIV infection has been associated with a marked reduction in the incidence of most opportunistic infections. From April 2001 to February 2002, 80 blood samples from patients who were suspected to have disseminated mycobacterial infection, presenting fever and (preferably) a $\mathrm{CD}_{4} \mathrm{~T}$ cell count $\leq 100.0$ cell $/ \mu \mathrm{L}$ were investigated. Twelve $(15 \%)$ of the 80 blood cultures were positive for mycobacteria, with Mycobacterium avium being identified in $7(8.8 \%)$ samples and $M$. tuberculosis in $5(6.2 \%)$. The $\mathrm{TCD}_{4}^{+}$count at the time of $M$. avium bacteremia ranged from 7 cells/ $\mu \mathrm{L}$ (average of 48.5 cell/ $\mu \mathrm{L}$ ), while in $M$. tuberculosis bacteremia it ranged from 50.0 cells $/ \mu \mathrm{L}$ (average of 80.0 cell/ $\mu \mathrm{L}$ ). The prevalence of M. avium bacteremia in our study follows the expected decline in opportunistic infections observed after the introduction of HAART; however, mycobacteremia by M. tuberculosis still indicates a high prevalence of tuberculosis infection in AIDS patients.
\end{abstract}

Key Words: Bacteremia, M. avium, M. tuberculosis, AIDS.

Infections with mycobacteria are frequent in individuals with AIDS [1]. Mycobacterium avium and M. tuberculosis are both common in opportunistic infections. The introduction of highly active antiretroviral therapy (HAART), defined as a combination of antiretroviral regimens that include either a potent viral protease inhibitor or a non-nucleoside reverse transcriptase inhibitor, has dramatically changed the clinical prognosis for human immunodeficiency virus (HIV)-infected patients in terms of decreased mortality, morbidity, and need for hospitalization [2]. In the preHAART era, infection with M. avium was detected in $50 \%$ of autopsied patients [3], but only $12 \%$ of the

Received on 27 July; revised 30 October 2005.

Address for correspondence: Dr.S.M. Nakatani. LACENPR (Laboratório central do Estado). Ubaldino do Amaral, 545, Alto da XV. Zip code: 80060-190, Curitiba, PR, Brazil. Phone: (55 41) 264-4111 (r.216). Fax: (55 41) 264-4448. Email: suenakatani@yahoo.com.

The Brazilian Journal of Infectious Diseases 2005;9(6):459-463 (C) 2005 by The Brazilian Journal of Infectious Diseases and Contexto Publishing. All rights reserved. patients with a suspicion of $M$. avium infection had positive blood cultures [4]. The detection of $M$. tuberculosis in blood samples is less frequent; its determination is only indicated for patients with severe immunosuppression or with suggestive clinical symptoms [5]. A decline in the frequency of M. avium and $M$. tuberculosis infections has been associated with the introduction of HAART and changes in $\mathrm{CD}_{4}$ cell count in various studies, although these studies also analyzed various types of samples other than blood [6]. However, it is still uncertain whether after antiretroviral regimens, the prevalence of $M$. tuberculosis infection in AIDS patients would be comparable in regions with a low prevalence of latent TB infection and a low risk of transmission of $M$. tuberculosis, compared with developing countries, where co-infection of HIV with $M$. tuberculosis is very common [7]. We determined the prevalence of $M$. avium and M. tuberculosis mycobacteremia in AIDS patients in the Brazilian state of Paraná, where $M$. tuberculosis is still highly prevalent. 


\section{Material and Methods}

$\underline{\text { Patients }}$

From April 2001 to February 2002, 80 patients (49 men and 31 women), with a median age of 32 years (range 7 to 64 years), who were suspected to have disseminated mycobacterial infection, presenting fever, and preferably a CD4 T cell count $\leq 100$ cells/ $\mu \mathrm{L}$, were investigated. All patients were under HAART therapy and originated from infectious disease clinics at different hospitals in Curitiba, Paraná, Brazil. The diagnosis of HIV infection was established on the basis of two positive enzyme-linked immunosorbent assays (ELISA) and confirmed by Western blot (immunoblot) analysis. The study was approved by the ethics committee of the Hospital de Clínicas, and informed consent was obtained from all patients before their inclusion in this study.

\section{$\underline{\text { CD4 Lymphocyte counts }}$}

They were made using fluorescein-labelled murine monoclonal antibodies (Becton-Dickinson Imunotech-Caxter San Jose Calif. USA) in a flow cytometer (FACS Count TM Reagents, BectonDickinson-San Jose Calif. USA).

\section{Processing of clinical samples}

Five milliliters of peripheral blood was inoculated into $\mathrm{MB} / \mathrm{BacT} \AA$ bottles (BacT/alert Microbial Detection Systems, Bio Merieux, Durham, NC, USA), $1 \mathrm{~mL}$ of enrichment fluid was added, and the bottles were incubated at $37^{\circ} \mathrm{C}$ for 42 days and continuously monitored for microbial growth (BacT/ALERT Microbial Detection Systems). Samples positive for microbial growth were screened by Ziehl-Gabbet staining, a modified Ziehl-Neelsen method [8] and submitted to DNA extraction immediately after the system signaled positive growth. Approximately 250 $\mu \mathrm{L}$ of the blood culture fluid was inoculated onto two solid Löwenstein-Jensen slants. The slants were incubated at $37^{\circ} \mathrm{C}$ in ambient air for up to eight weeks.
Mycobacteria were identified by classical biochemical tests [9].

$\underline{\text { PCR }}$

All the samples were processed by PCR, which was performed as previously described [10].

\section{Results}

Twelve (15\%) of the 80 blood cultures were positive for mycobacteria, with $M$. avium being identified in seven samples and $M$. tuberculosis in five. Positive blood cultures were detected by the BacT/ ALERT system after a mean incubation time of 9.5 days for $M$. avium and of 16.7 days for $M$. tuberculosis. All 12 positive blood cultures were confirmed by Ziehl-Gabbet bacilloscopy and after culture on solid Löwenstein-Jensen medium using the appropriate biochemical tests. In addition, two cultures (2.5\%) were positive for Cryptococcus sp. and one culture $(1.25 \%)$ was positive for Candida sp.

Seventy-four patients $(92.5 \%)$ presented $\mathrm{TCD}_{4}{ }^{+} \leq$ 100.0 cells $/ \mu \mathrm{L}$ and six patients $(7.5 \%)$ had $\mathrm{TCD}_{4}>$ 100.0 cells/ $\mu \mathrm{L}$. Mycobaterium avium bacteremia was detected with $\mathrm{TCD}_{4}{ }^{+}$ranging from 7.0 cells $/ \mathrm{mL}$, with an average of 48.5 cells $/ \mathrm{mL}$, while bacteriemia by $M$. tuberculosis was detected with $\mathrm{TCD}_{4}^{+}$counts from 50 cells $/ \mathrm{mL}$, and average of 80 cells $/ \mathrm{mL}$ (Table 1 ).

Detection of $M$. avium and $M$. tuberculosis from positive blood cultures by PCR showed $100 \%$ agreement with the culture results, as has been previously described [10].

\section{Discussion}

We found mycobacteremia in 15\% (12/80) of the AIDS patients who had clinical symptoms, such as fever and preferably $\mathrm{CD}_{4}<100$ cells $/ \mu \mathrm{L}$. It is well know that susceptibility to opportunistic infections increases as HIV-induced immunodeficiency becomes more severe. 
Table 1. Demographic profile, $\mathrm{TCD}^{+}{ }^{+}$count, and mycobateria species isolated from blood cultures of AIDS patients

\begin{tabular}{ccccc}
\hline Sample identification & Age (years) & Sex & TCD $_{\mathbf{4}}^{+}$cells/ $\boldsymbol{\mu L}$ & Mycobacterial species \\
\hline 515 & 34 & M & 7 & M. avium \\
583 & 46 & F & 25 & M. avium \\
539 & 41 & M & 34 & M. avium \\
505 & 39 & F & 38 & M. avium \\
513 & 12 & F & 82 & M. avium \\
582 & 31 & M & 112 & M. avium \\
521 & 40 & M & 311 & M. avium \\
519 & 23 & F & 50 & M. tuberculosis \\
522 & 33 & M & 55 & M. tuberculosis \\
509 & 32 & M & 94 & M. tuberculosis \\
541 & 25 & F & 95 & M. tuberculosis \\
569 & 27 & M & 108 & M. tuberculosis \\
\hline
\end{tabular}

M. = Mycobacterium.

Among patients with HIV infection, $\mathrm{T}^{+} \mathrm{CD}_{4}$ lymphocyte counts continue to be the best-validated predictor of opportunistic infection [2]. Before HAART was available, patients with $\mathrm{CD}_{4}$ cell counts above 200 cells/ $\mu \mathrm{L}$ were found to be at low risk for the majority of AIDS-defined opportunistic infections, with an increased individual risk with decreases in the $\mathrm{CD}_{4}$ cell count [2]. Nightingale et al. observed that $39 \%$ of patients with $M$. avium infection presented $\mathrm{CD}_{4} \leq 10.0$ cells $/ \mu \mathrm{L}$, while the infection occurred in only 1 to $3 \%$ of patients with $\mathrm{CD}_{4} 100$ to 199 cells $/ \mu \mathrm{L}$. On the other hand, infection by $M$. tuberculosis seems to occur when the $\mathrm{CD}_{4}$ cell count is around 200 to 300 cells/ $\mu \mathrm{L}$ [11], and the extra-pulmonary form can appear when $\mathrm{CD}_{4}$ is even lower, around 15 to 114 cells/ $\mu \mathrm{L}$ [12]. In our investigation, one of the inclusion criteria was $\mathrm{TCD}_{4}^{+}$ count $\leq 100$ cells $/ \mu \mathrm{L}$. Mycobacteremia by $M$. avium was detected in patients with $\mathrm{TCD}_{4}{ }^{+}$counts ranging from 7.0 cells $/ \mu \mathrm{L}$, with an average of 48.5 cells $/ \mu \mathrm{L}$ (Table 1). This average does not include a patient who presented an $M$. avium infection with a $\mathrm{CD}_{4}$ count of 311 cells $/ \mu \mathrm{L}$. On the other hand, M. tuberculosis infection occurred in patients with $\mathrm{TCD}_{4}^{+}$higher than 50 cells $/ \mu \mathrm{L}$, with an average of 80 cell $/ \mu \mathrm{L}$. Our data indicates that as immunosuppression becomes more intense, the patients were more susceptible to M. avium and extra-pulmonary forms of M. tuberculosis infections.

There are only a few studies on the prevalence of mycobacteremia in AIDS patients in Brazil. Some of these reports are retrospective studies analyzing different types of clinical samples [14]. Our calculated prevalence of mycobacteria infection (15\%) was higher than that observed by Aily et al. [13], who analyzed blood samples of 1,521 patients with $\mathrm{CD}_{4}<100$ cells/ $\mu \mathrm{L}$ from Instituto Adolfo Lutz (São Paulo) from 1994 to 1997 , and found $9.9 \%$ mycobacteremia. In addition, Ramos et al. [14] in 1996 and Barreto et al. [15] from 1990 to 1992 found $22.0 \%$ and $25.6 \%$ mycobacterial infection, respectively, in patients from São Paulo. The difference in the prevalence of mycobacteremia between earlier and recent studies is probably related to the introduction of HAART in 1997. After the introduction of this therapeutic scheme, various studies have demonstrated a significant decrease $(>50 \%)$ in opportunistic infections between 1992 and 1997, especially those caused by $M$. avium and Cytomegalovirus [2]. In addition, HAART has had a strong impact on the decline of mortality, which fell from 21.9/100 in 1994 to 3.7/100 in 1997 [16]. 
Regarding the species of mycobacteria observed in our study, the prevalence of $M$. avium (8.8\%) was similar to that observed for M. tuberculosis (6.2\%). Although the prevalence of $M$. avium mycobacteremia was lower than those reported in previous investigations, in which it ranged from $15 \%$ to $24 \%$ [17], the rate was similar to that recently reported by Jacomo et al. [18], with only $5 \%$ of blood samples tested being positive for M. avium.

On the other hand, when we analyzed the frequencies of $M$. avium $(7 / 12,58 \%)$ and M. tuberculosis $(5 / 12,42 \%)$ in positive samples, they were similar to those reported by Aily et al., with $53.8 \%$ of blood samples positive for M. avium. Using various clinical samples, such as spit, blood, biopsies and cerebral-spinal fluid, Ramos et al., found $45 \%$ positivity for M. avium and 55\% for M. tuberculosis. This difference in incidence is likely to be due to the type of sample used and indicates that the source of material can strongly influence the results in the detection of mycobacterial species. In another study in 1995 (pre HAART), positive mycobacteremias were more frequently due to M. avium (59.2\%) than M. tuberculosis (28.6\%); whereas in 1998 (HAART era), the relative frequencies were reversed (28.6 vs. $64.3 \%$ respectively [19]. While $M$. avium mycobacteremia has been reported by various authors, data on M. tuberculosis mycobacteremia are scarce. In industrialized countries, mycobacteremia is mainly caused by $M$. avium, and in developing countries, it is generally caused by M. tuberculosis [12]. In Africa, mycobacteremia by M. tuberculosis is very prevalent ( $28 \%$ to $46 \%$ ), while bacteremia by M. avium occurs in $10 \%$ of the cases [20]. The high prevalence, and consequently the high degree of exposure of $M$. tuberculosis in developing countries, may be the main factor for this rate. On the other hand, M. avium is ubiquitous in nature and only causes disease in individuals with immune deficiencies, such as AIDS [17].

In the present study, the findings of $M$. avium and $M$. tuberculosis infection detected are in agreement with the decline in opportunistic infections observed after the introduction of HAART, specially due to
M. avium. Bacteremia caused by M. tuberculosis was uncommon until the advent of AIDS, and most studies have been based on a small number of patients. Our data of $M$. tuberculosis mycobacteremia suggest that although therapy, the infection is frequent particularly in AIDS patients who are not compliant to HAART or have resistance to current antiretroviral therapy. These findings more likely are related to the high prevalence of the disease in our enviroment with consequently more reactivation cases. However, for continuous monitoring of the incidence of AIDS-defining events in the post-HAART era, larger studies are needed, in order to established the real reduction of mycobacterial infection in these patients.

\section{Reference}

1. Montessori V., Philips P., MontanerJ., et. al. Species distribution in human imunodeficiency virus-related mycobacterial Infections: implications for selection of initial treatment. Clin Infec Dis 1996;22:989-92.

2. Kovacs J.A., Masur H. Prophilaxis against opportunistic infections in patients with human immunodeficiency virus infection. N Engl J Med 2000;346:1416-29.

3. Wallace J.M., Hannah J.B. M. avium complex infection in patients with the acquired immunodeficiency syndrome. A clinicopathologic study. Chest 1988;93:926-8.

4. Nihtingale S., Byrd L.T., Southern P.M., et. al. Incidence of $M$. avium-intracellulare complex bacteremia in human immunodeficiency virus-positive patients. J Infect Dis 1992: 1082-1085.

5. Reimer L.G., Wilson M.L., Weinstein M.P. Update on detection of bacteremia and fungemia. Clin Microbiol Rev 1997; 10:444-65.

6. Ole K., Gatell M.J., Mocrofoft A., et. al. Infection with mycobacterium tuberculosis and Mycobacterium avium among HIV-infected Patients after the Introduction of Highly Active Antiretroviral Therapy. Am J Respir Crit Care Med 2000; 162:865-72.

7. Lopes-Santoro G., Pinho A.M.F., Harrison L.H. Schecter M. Reduced risk of tuberculosis among Brazilian patients with advanced human immunodeficiency virus infection treated with highly active antiretroviral therapy. Clinical Infectious Disease 2002;34:543-6.

8. Costa H.C., Souza L.C., Martini J.P., et. al. Comparative study of various staining methods for mycobacteria. Hansenol Int. 1988;3:37-41. 
9. Metchock B.G., Nolte F.S., Wallace R.J. Mycobacterium, p.399-439, In: P. R. Murray, E. J. Baron, M. A. Pfaller,F.C Tenover, and R.H. Yolken(ed.), Manual of clinical microbiology, 7th ed. Washington, D.C: American Society for Microbiology, 1999.

10. Nakatani S.M., Burger M., Messias-Reason I.J.T., et. al. Efficiente method for mycobacterial DNA extraction in blood cultures aids rapid identification of $M$. tuberculosis and M. avium. Euro J Clin Microbiol Infect Dis 2004;23:851-4.

11. Cock K.M. Research issues involving HIV-associated tuberculosis in resource poor countries. JAMA 1996;276:1502-7.

12. Reyn C.F. The significance of bacteremic tuberculosis among persons with HIV infection in developing countries. AIDS 1999; 13:2193-5.

13. Aily D.C., Camargo S.S., Paro H.S., et al. Systematic mycobacteriosis in AIDS patients as determined by blood cultures on biphasic medium. Rev Argent Microbiol 1999;31:53-7.

14. Ramos M.C., Vilares M.C.B., Moraes M.J., et al. A retrospective bacteriological study of mycobacterial infections in patients with acquired immune deficiency syndrome (AIDS). Brazilian J Infec Dis 2000;2:86-90.

15. Barreto J.A., Palaci M., Ferrazoli L., et al. Isolation of Mycobacterium avium complex from bone marrow aspirates of AIDS patients in Brazil. J Infect Dis 1993; $168: 777-9$.

16. Palella F.J. Declining morbidity and mortality among patients with advanced human immunodeficiency virus infection. N Engl J Med 1998;338:853-60.

17. Horsburgh C.R.M. avium complex infection in the acquired immunodeficiency syndrome. N Engl J Med 1991;324:1332-8.

18. Jacomo V., Musso D., Gevaudan M.J., Drancourt M. Isolation of blood-borne $M$. avium by using the nonradioactive Bactec $9000 \mathrm{MB}$ System and comparison with a solid- culture system. J Clin Microbiol 1998;36:3703-6.

19. Hadad DJ., Palaci M., Pignatari A.C., et. al. Mycobacteraemia among HIV-1-infected patients in São Paulo, Brazil:1995 to 1998. Epidemiolo Infect 2004; $132: 151-5$.

20. Gotteberg A., Sacks L., Mahala S., et. al. Utility of blood cultures and incidence of micobacteremy in patients with suspected tuberculosis in South African infectious disease referral hospital. Int J Tuberc Lung Dis 2000;5:80-6. 